\title{
EPOXIDAÇÃO QUIMIO-ENZIMÁTICA DE ÓLEO DE GIRASSOL E CANOLA BRUTOS VISANDO O EMPREGO EM PROCESSOS DE USINAGEM
}

\author{
Manuella Schneider', \\ Rosana de Cassia de Souza Schneider ${ }^{1-2}$, \\ André Luiz Klafké, \\ Wolmar Alípio Severo Filho ${ }^{1}$
}

\section{RESUMO}

Os processos de transformação em oleoquímica utilizando biocatalisadores são alternativas para utilização de metodologias mais limpas e para a realização de conversões mais seletivas. Neste trabalho investigou-se a produção de ésteres metílicos epoxidados provenientes dos óleos de girassol e canola visando a sua utilização na formulação de fluidos utilizados em usinagem. 0 sistema catalítico quimio-enzimático de epoxidação foi mediado pela lipase de Candida antarctica B (CALB $-1000 \mathrm{u} / \mathrm{g}$ ) e peróxido de hidrogênio $30 \%(\mathrm{v} / \mathrm{v})$. Os resultados obtidos a partir das análises de RMN ${ }^{1} \mathrm{H}$, CG-EM e Índice de iodo mostraram que a conversão chegou à $>99 \%$ após $24 \mathrm{~h}$ de reação utilizando ésteres metílicos dos óleos brutos. Os produtos obtidos a partir do óleo de canola e de girassol brutos apresentam-se em condições de testagem em formulações para usinagem.

Palavras-chave: Epóxidos. Biocatálise. Girassol. Canola.

\section{ABSTRACT}

The oleochemical transformation processes using biocatalysts are alternatives to the use of cleaner methodologies and for performing more selective conversions. In this study we investigated the production of epoxidized methyl esters from sunflower and canola oils for their application in the formulation of fluids used in machining. The catalytic system of chemoenzymatic epoxidation was mediated by lipase from Candida antarctica B (CALB $-1000 \mathrm{u} / \mathrm{g}$ ) and hydrogen peroxide $30 \% \mathrm{v} / \mathrm{v}$ ). The results obtained from the analysis of NMR ${ }^{1} \mathrm{H}, \mathrm{GC}-\mathrm{MS}$ and iodine value showed that the conversion reached $>99 \%$ after $24 \mathrm{~h}$ of reaction using methyl esters of crude oils. The

1 Departamento de Química e Física - Universidade de Santa Cruz do Sul, RS, Brasil, manuellasch@hotmail.com

2 Programa de Pós-graduação em Tecnologia Ambiental - Universidade de Santa Cruz do Sul, RS, Brasil. 
products obtained from canola and sunflower crude oil present testing conditions in the machining formulation.

Keywords: Epoxides. Biocatalysis. Sunflower. Canola.

\section{INTRODUÇÃO}

As preocupações com o meio ambiente e a crescente poluição fazem com que estudos de novos processos tenham uma atenção maior visando a utilização de tecnologias mais limpas. Uma importante alternativa para obtenção de vários produtos, diminuindo o impacto ambiental são os processos biocatalíticos, particularmente o uso de enzimas.

As enzimas são geralmente protéicas e a maioria produzida pela fermentação em um material de base biológica. (LOUWRIER, 1998) Milhares de enzimas que possuem substratos específicos são conhecidas, porém, somente uma pequena quantidade tem sido isolada na forma pura, assim como há pouco conhecimento de sua estrutura e função. (HASAN, 2005)

Os benefícios oferecidos pelas enzimas são especificidade, condições suaves e redução de perdas. Pode ser possível, escolhendo a enzima correta, controlar quais substâncias produzir. Dessa forma, a planta industrial concebida para realizar reações quimio-enzimáticas pode ser construída e operada com menor investimento e menos custo com energia e tratamento de resíduos. (HASAN, 2005)

Em 1856, Claude Bernard descobriu lipases no suco pancreático, mas elas somente foram usadas de forma isoladas em processos industriais em 1908, por Rohm em tratamentos de couro e em 1911, por Wallterstein na produção de cerveja. (HASAN, 2005; CHEETAM, 1995)

Conforme as regras oficiais de classificação, as enzimas são divididas em seis grupos de acordo com tipo de reação que catalisam. As lipases constituem um importante e valorizado grupo, principalmente por causa de sua versatilidade e fácil produção em massa. (HASAN, 2005).

O uso desse grupo de enzimas como biocatalisadores vem sendo explorado recentemente, potencialmente aplicado em indústrias de alimentos, detergentes, farmacêuticos, couros, têxteis, cosméticos e papéis, entre outros. Dessa forma, há grandes expectativas de que nos próximos anos os químicos continuarão a se beneficiar dessa versatilidade. (BJÖRKLING et al., 1992 ; LARA, 2006)

As lipases (triglicerol acil-hidrolases, EC 3.1.1.3) são parte da família das hidrolases que atuam sobre ligações de éster carboxílico. Elas catalisam a hidrólise total ou parcial de triacilglicerol fornecendo diacilgliceróis e monoacilgliceróis, bem como glicerol e ácidos graxos livres. (HASAN, 2005; 
CARVALHO, 2002; NETO, 2002) Devido ao baixo teor de água utilizado nessas reações, esterificação e transesterificação também podem ser realizadas.(SALIS et al., 2005)

O comportamento regio-, quimio- e enantiosseletivo tem provocado grande interesse em pesquisadores e segmentos industriais. A regiosseletividade possibilita a distinção entre outros grupos funcionais somente com a mudança do meio reacional; a quimiosseletividade determina a atuação em somente um tipo de grupo funcional mesmo em presença de outros grupos reativos; também são enantiosseletivas, com a atuação na catálise quiral e a especifidade pode ser explorada para sínteses seletivas assimétricas.(LARA, 2006; SAXENA; DAVIDSON, 2003)

A área de biocatálise emergiu como uma ferramenta poderosa para a chamada química verde, o qual leva as indústrias a se comprometerem com o controle ambiental.( CONTI; MORAN, 2001) Entre as potencialidades de uso das lipases como biocatalisadoras estão as transformações oleoquímicas. Entre as aplicações na oleoquímica, a mais importante é a produção de ácidos graxos a partir de óleos, os quais são importantes intermediários em reações dessa indústria. (AL-ZUHAIR et al., 2004)

Algumas gorduras são muito mais valorizadas que outras devido a sua estrutura e os óleos podem ser convertidos em espécies mais úteis, por exemplo, a produção de manteiga de cacau a partir do fracionamento do óleo de palma ( AU-KBC, 2011).

A estrutura de triacilgliceróis dos óleos vegetais proporciona qualidades desejáveis em um lubrificante. Longas cadeias de ácidos graxos fornecem alta resistência em um filme lubrificante, no qual ocorre uma intensa interação com superfícies metálicas, reduzindo o atrito e desgaste. Uma preocupação é a suscetibilidade de ocorrer hidrólise e oxidação do óleo, sendo assim, quantidade excessiva de água, aquecimento e contato com o ar devem ser evitados, para reduzir a formação de derivados indesejáveis. ( ERHAN, 2006)

Em busca de solucionar essa deficiência, os epóxidos despertam grande interesse aos químicos por serem importantes intermediários na obtenção de diversos compostos. Esta versatilidade está associada à eliminação da ligação dupla do ácido graxo com a inserção de um oxigênio, formando um anel oxirano.(CASTANHEIRA et al., 2011)

O método tradicional de epoxidação deve ser conduzido sobre uma condição ótima de operação se o desejo é atingir a seletividade, além disso, são realizadas com ácidos peroxicarboxílicos, como ácido peracético, ácido perfórmico e ácido perbenzóico. Estas metodologias apresentam perigo de manuseio em escala industrial, além do alto impacto ambiental devido ao descarte de efluentes do processo. (ARAMENDÍA et al., 2008; NUNES et al., 2008) 
No método químio-enzimático, certos perácidos oxidam a dupla ligação $\mathrm{C}=\mathrm{C}$, quebrando a ligação $\pi$, formando os ácidos percaboxílicos insaturados. Estes são apenas intermediários da reação e se auto epoxidam em bons rendimentos sem reações consecutivas.(LARA, 2006; WARWEL; KLAAS, 1995)

$\mathrm{Na}$ última década, a indústria vem tentando formular lubrificantes biodegradáveis com características superiores dos usuais baseados em óleo mineral. Dessa forma, além da catálise natural, os óleos vegetais são promissores candidatos como fluido de base em lubrificantes a fim de atingir a sustentabilidade ambiental. (EHRAN; ASADAUSKAS, 2000)

Alternativas pesquisadas incluem lubrificantes sintéticos, sólidos e de origem vegetal. Devido ao potencial do óleo vegetal, há a possibilidade de serem produzidos novos produtos que mantenham propriedades semelhantes as dos produtos totalmente sintéticos e derivados de matrizes de origem fóssil.

Entre estes produtos estão o éster metílico epoxidado e o biodiesel, que podem ser obtidos de diferentes óleos vegetais, os quais são de fonte renovável e contribuem para a captura de carbono da atmosfera. Se os óleos vegetais são submetidos a modificações químicas em sua estrutura, passam a ser uma alternativa mais viável de uso. (CAMPANELLA et al., 2010)

Os derivados dos óleos vegetais, funcionalizados ou não, podem ser utilizados em misturas que compõem fluidos utilizados em atividades de usinagem. Os fluidos de corte foram empregados para melhorar o desempenho dos processos de usinagem e ganharam tal importância, sendo essenciais para a obtenção da qualidade exigida nas peças produzidas. Os fluidos introduzem uma série de melhorias funcionais e econômicas no processo de usinagem de metais. Principalmente, redução do coeficiente de atrito, refrigeração e impedimento da corrosão da peça usinada. (ZEILMANN, 2011)

Entretanto, com uma composição química complexa, os fluidos de corte tiveram um aumento proporcional de riscos ambientais e ocupacionais. Bactérias e fungos presentes podem, inclusive, gerar toxinas. (ZEMAN et al., 1995) Portanto, a utilização de fluidos de corte no processo de usinagem faz da indústria metal-mecânica uma potencial agressora do meio ambiente.(OLIVEIRA; ALVES, 2007)

Com base nisso, este trabalho tem como objetivos a produção de éster metílico epoxidado visando a sua inserção na formulação de fluidos de corte em operações de usinagem e desta forma contribuir para aumentar a composição renovável destes fluidos e aproveitar a capacidade produtiva local, utilizando óleo de girassol e de canola brutos, que possam ser produzidos por agricultores familiares. 


\section{METODOLOGIA}

\subsection{Produção de ésteres metílicos dos óleos de canola e girassol}

Os ésteres metílicos, material de partida para as reações de epoxidação quimioenzimática foram produzidos previamente pela transesterificação do óleo de girassol e canola na planta piloto de produção de biodiesel da UNISC. (PORTE et al., 2010)

\subsection{Procedimento de epoxidação químioenzimática}

O procedimento foi realizado em sextuplicata com o éster metílico dos óleos de girassol e de canola. Para a reação, em um erlenmeyer com capacidade de $500 \mathrm{~mL}$ foram adicionados $100 \mathrm{~g}$ de biodiesel, $200 \mathrm{~mL}$ de diclorometano (DCM), $200 \mathrm{~mL}$ de água deionizada, $100 \mathrm{~mL}$ de peróxido de hidrogênio $30 \%$ e $10 \mathrm{~g}$ de lipase Novozyme $M 435 \AA$. Em seguida, a amostra foi colocada no Shaker para agitação orbital M42 da marca Marconi por $24 \mathrm{~h}$ a $30^{\circ}$ C. Após essa duração, a enzima foi filtrada com lã de vidro em um funil simples e recolhida em um funil de separação, a fim de separar a fase contendo o produto de reação e solvente orgânico, da fase aquosa. Para retirar o diclorometano desta fase, a amostra foi rota evaporada, restando somente 0 óleo epoxidado.

\subsection{Teste do índice de Iodo}

Pesou-se cerca de $0,2 \mathrm{~g}$ da amostra, em um erlenmeyer de $250 \mathrm{~mL}$, o qual se adicionou $15 \mathrm{~mL}$ da solução de ácido acético/cicloexano 1:1. Posteriormente, pipetou-se $25 \mathrm{~mL}$ da solução de WIJS no frasco contendo a amostra e fechou-se o erlenmeyer em imediato. Deixou-se o erlenmeyer no escuro por $1 \mathrm{~h}$. Em seguida, adicionou-se $20 \mathrm{~mL}$ da solução de iodeto de potássio a $10 \%$ e $100 \mathrm{~mL}$ de água deionizada. Titulou-se com tiossulfato de sódio $0,1 \mathrm{~mol} \mathrm{L-1}$, gotejando até o aparecimento de cor laranja. Então, adicionou-se $2 \mathrm{~mL}$ de solução de amido $1 \%$ e continuou-se a titulação até o desaparecimento da cor azulada. Preparou-se a determinação em branco para cada grupo de amostras. Os valores gastos na titulação da amostra e do branco foram devidamente anotados e utilizados no cálculo. O índice de iodo foi expresso em gramas de iodo absorvido em $100 \mathrm{~g}$ de amostra.

\subsection{Ressonância Magnética Nuclear (RMN) de ${ }^{1} \mathrm{H}$}

Os espectros de RMN $1 \mathrm{H}$ foram obtidos nos espectrômetros Bruker AC 200 MHz, Varian XL-200 e DBX $200 \mathrm{MHZ}$. As amostras foram preparadas em CDCl3, utilizando-se como referência o tretrametilsilano (TMS).

A conversão das duplas ligações em respectivos oxiranos foi reconhecida por RMN $1 \mathrm{H}$ utilizando a equação da Figura 1 . A é o valor da integral da área do singleto dos hidrogênios ligados aos carbonos da dupla ligação (hidrogênios em azul, 5,40 ppm) e B é o valor da integral da área do singleto dos 
hidrogênios ligados aos carbonos do anel oxirano (hidrogênios em 3,10 ppm e $2,90 \mathrm{ppm})$.

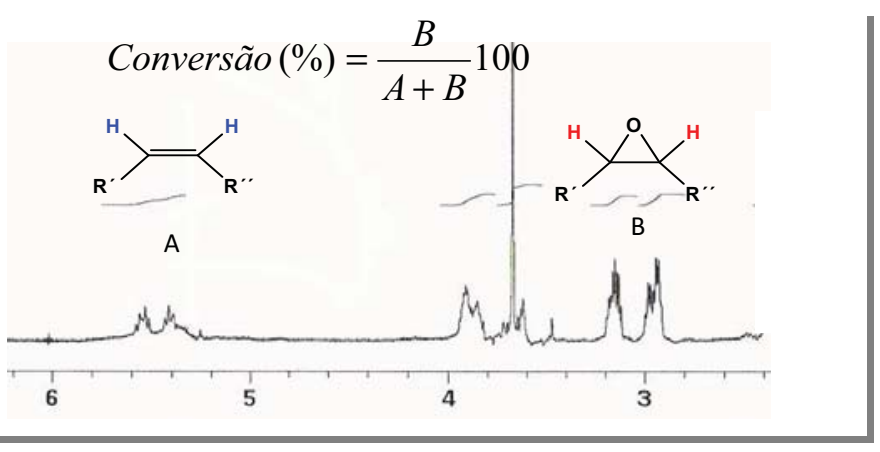

Figura 1. Espectro de RMN ${ }^{1} \mathrm{H}$ de óleo de mamona epoxidado.

\subsection{Cromatografia Gasosa acoplada a espectrometria de massas (CG-EM)}

A análise por CG-EM foi realizada em um equipamento Shimadzu QP 2010 plus com coluna RTz 5 MS (30 m x 0,25 mm x 0,25 $\mu \mathrm{m})$. Para a identificação dos componentes da amostra foi realizada a análise por similaridade com os espectros da biblioteca Wiley 229.

\subsection{Testes preliminares de emulsão para uso em fluidos de corte}

Para testar os epoxidos quanto a possibilidade de formação de emulsões, foi realizado um teste em laboratório que consistiu em adição de $20 \mathrm{ml}$ água destilada, $10 \%$ oleo epoxidado e concentrações variáveis de twen $80(1 \%, 25$, $4 \%, 6 \%)$. As misturas foram colocadas em shaker com agitação orbital.

\section{RESULTADOS E DISCUSSÃO}

Para o aumento de escala nas reações de epoxidação químio-enzimática foram realizados experimentos em triplicata para as reações de epoxidação químio-enzimática. A Figura 2, mostra o espectro do produto da reação partindo de $100 \mathrm{~g}$ de óleo, onde foi possível observar a inexistência de sinais na região de 5,30 ppm, característica dos hidrogênios vinílicos das duplas ligações e a presença de sinais na região de 2,90 à 3,10 ppm, característico dos hidrogênios metínicos do grupamento oxirânico do epóxidos, indicando que a reação de epoxidação se completou mesmo com um aumento de escala, uma vez que anteriormente havia sido realizado com massas de até $5 \mathrm{~g}$.

A reprodução deste resultado com diferentes óleos e com usos repetidos da enzima é importante uma vez que, o emprego dos óleos pode ser conforme a oferta em períodos de safra agrícola. Com base nisso os resultados encontrados para a conversão dos óleos de girassol e canola estão apresentados na Tabela 1. Estes resultados são obtidos com os óleos brutos extraídos de sementes produzidas na região do Vale do Rio Pardo -RS. 
Neste teste preliminar de reutilização de enzima observa-se que há uma variação nos valores encontrados, no entanto, estes valores estão mais relacionados ao sistema de agitação do que a desnaturação da enzima, uma vez que, com óleo de girassol refinado já havíamos realizado um reuso de 10 vezes da mesma enzima, com a mesma metodologia.

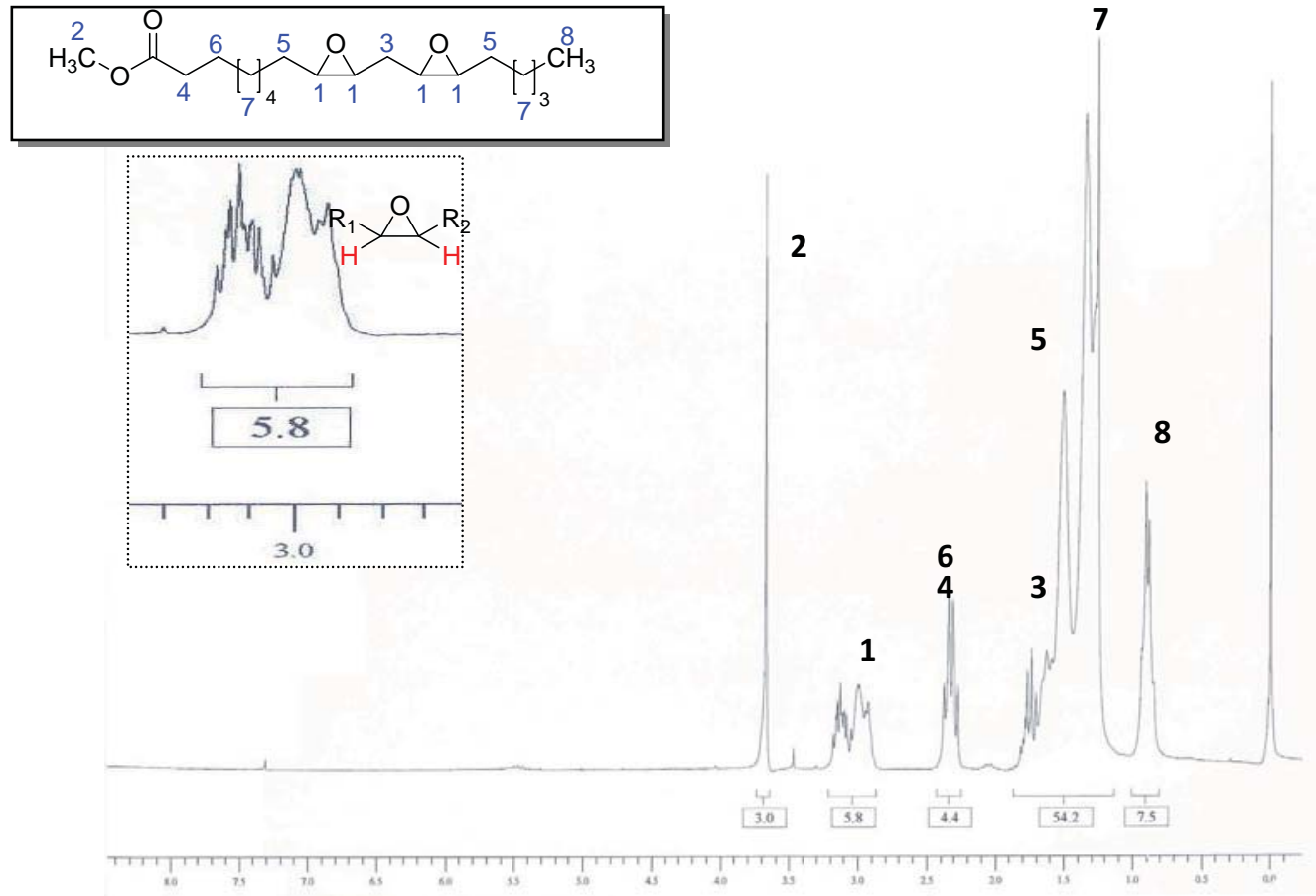

Figura 2. RMN ${ }^{1} \mathrm{H}$ EMG epoxidado com 24h de reação em Shaker orbital.

Tabela 1. Conversão dos ésteres metílicos em ésteres metílicos epoxidados.

\begin{tabular}{lll}
\hline \multirow{2}{*}{ Óleos vegetais } & \multicolumn{2}{l}{ Conversão (\%) } \\
\cline { 2 - 3 } & Enzima nova & Reutilização da enzima \\
\hline Girassol 1 & 100,0 & 99,4 \\
Girassol 2 & 100,0 & 92,7 \\
Girassol 3 & 39,9 & 85,0 \\
Canola 1 & 76,0 & 96,0 \\
Canola 2 & 62,3 & - \\
\hline
\end{tabular}

Assim, é de conhecimento que a utilização de $\mathrm{CH}_{2} \mathrm{Cl}_{2} / \mathrm{H}_{2} \mathrm{O}$ na epoxidação químio-enzimática com CALB, possa ser uma alternativa para redução da desnaturação desta lipase, pois acredita-se que a CALB fique dissolvida na fase aquosa diminuindo o contato com o solvente orgânico.

Os resultados encontrados na conversão dos óleos de canola e de girassol brutos em ésteres metílicos epoxidados podem ser observados nos espectros de RMN ${ }^{1} \mathrm{H}$ da Figura 3 . Nestes espectros se observam os sinais relativos à 
presença de grupos oxiranos presentes na cadeia carbônica dos produtos obtidos.

Dentre os produtos analisados por RMN ${ }^{1} \mathrm{H}$ foi possível constatar que, a partir do método de epoxidação químio-enzimático, obteve-se maior seletividade para a produção de epóxido, não sendo observado a abertura do anel oxirano. No sistema, os ésteres sofreram reação de peridrólise, formando perácidos e oxidando a mólecula de éster no meio reacional. Estes resultados foram confirmados por CG-EM, sendo que os produtos de epoxidação dos principais ésteres metílicos, provenientes do ácido oléico e linoléico, presentes nos dois óleos, foram observados em tempos de retenção de 24 a $30 \mathrm{~min}$ (Figura 4).

a

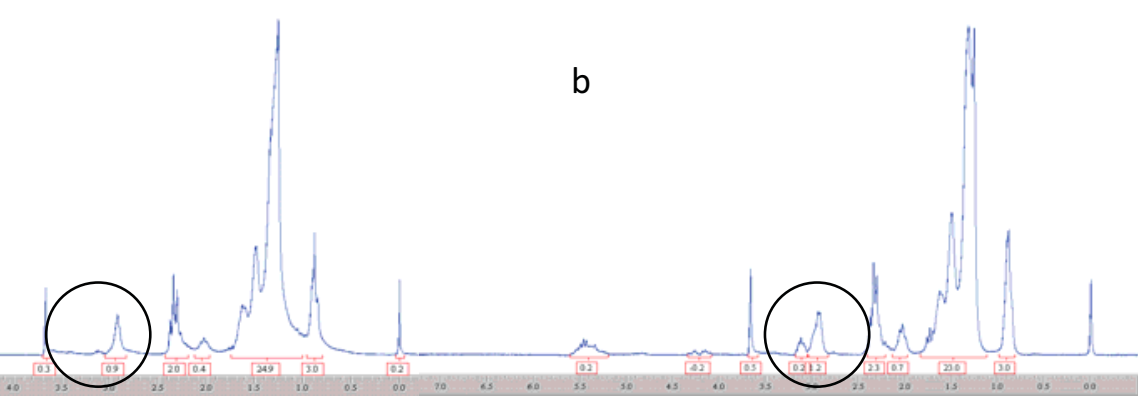

Figura 3. Espectros de RMN ${ }^{1} \mathrm{H}$ dos produtos epoxidados dos ésteres metílicos de canola (a) e girassol (b) brutos.

De acordo com os principais produtos identificados por CG-EM, é viável a produção de epóxidos a partir dos ésteres metílicos dos óleos de girassol e canola, considerando que eles apresentam um alto índice de acidez (acima de $5 \%$ ) levando a formação dos principais ésteres epoxidados apresentados na Figura 4.
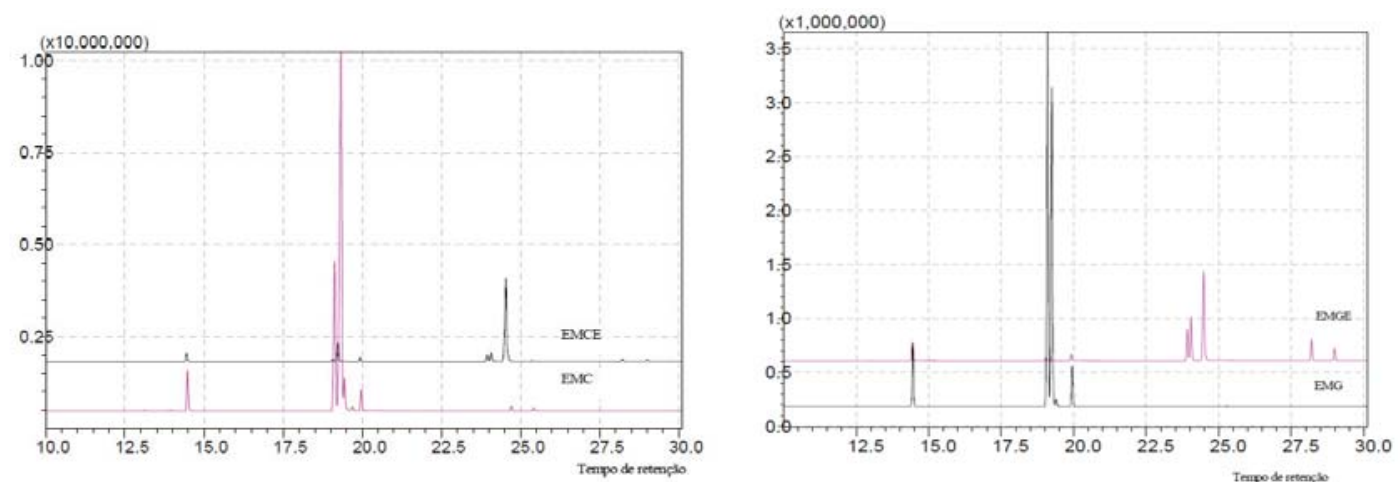

Figura 4. Cromatogramas dos ésteres metílicos do óleo de canola (EMC), de canola epoxidado (EMCE), de girassol (EMG) e de girassol epoxidado (EMGE).

Nos testes preliminares para preparação de emulsões necessárias na formulação dos fluidos para usinagem foi observado que após a formação da emulsão, o epóxido, apesar de ser de baixa polaridade permaneceu emulsionado em água como mostra a Figura 5. Este resultado foi observado 
para os ésteres metílicos epoxidados dos óleos de girassol e canola e indicam uma potencialidade de uso destas matérias-primas para a formulação dos fluidos de corte.

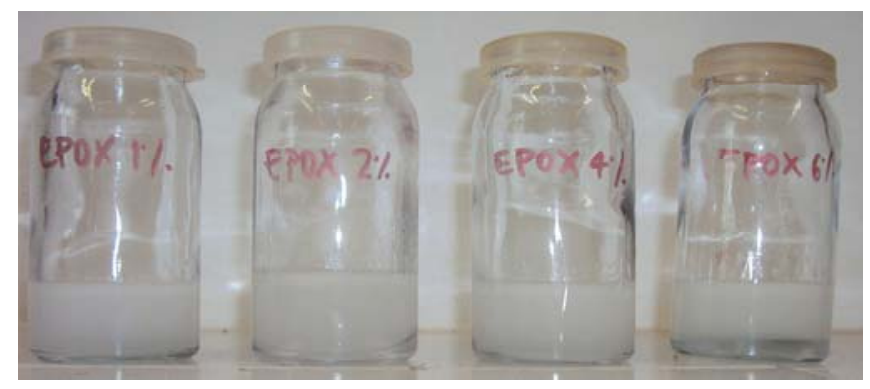

Figura 5. Emulsões com ester metílico de óleo de canola epoxidado.

\section{CONSIDERAÇÕES FINAIS}

Os óleos de canola e girassol foram transesterificados e epoxidados com sucesso, mesmo com o emprego de óleos brutos, o que dificultaria a aplicação em formulações comerciais se a conversão fosse parcial. As ligações duplas foram totalmente convertidas e não houve abertura dos anéis oxiranos durante a epoxidação. Desta forma os produtos obtidos, tanto a partir do óleo de canola como de girassol, apresentam potencialidade para uso em formulações de fluidos de corte. Destaca-se também que, além do método utilizado com os óleos brutos ser viável para a obtenção de ésteres epoxidados, não há necessidade de purificação do óleo antes da conversão, uma vez que a acidez do óleo é desejada para que as reações de epoxidação quimio-enzimáticas aconteçam. Por outro lado, os produtos epoxidados obtidos de diferentes óleos apresentam grau de epoxidação conforme o número de insaturação original, 0 que deverá ser avaliado nos futuros experimentos em formulações insdustriais, uma vez que é importante a possibilidade de uso de diferentes óleos, incentivando a diversificação.

\section{AGRADECIMENTOS}

PUICvol-UNISC, FAP-UNISC, FAPERGS, CNPq, SCT-RS e Pólo de Modernização Tecnológica do Vale do Rio Pardo.

\section{REFERÊNCIAS}

AL- ZUHAIR, S.; RAMACHANDRAN, K. B.; HASAN, M. High enzyme concentration model for the kinetics of hydrolysis of oils by lipase. Chemical Engineering Journal. v.103, n. 1-3, p. 7-11, 2004.

ARAMENDÍA, M.A, BORAU, V., JIMÉMEZ, C., LUQUE, J. M., MARINAS, J. M., RUIZ, J. R., URBANO, F. J. Epoxidation of limonene over hydrotalcite-like 
compounds with hydrogen peroxide in the presence of nitriles. Applied catalysis A: general. v. 216, n. 1-2, p. 257-265, 2001

AU-KBC Research centre. Applications of lipases. Disponível em: <http://www.au-kbc.org/beta/bioproj2/uses.html>. Acesso em 10 jan. 2011.

BJÖRKLING, F; FRYKMAN, H.; GODTFREDSEN, S. E.; KIRK, O. Lipase catalyzed synthesis of peroxycarboxylic acid and lípase mediated oxidations. Tetrahedron, v. 48, n. 22, p. 4587-4592. 1992.

CAMPANELLA, A. et al. Lubricants from chemically modified vegetable oils. Bioresource Technology v. 101, n. 1, p. 245-254, 2010.

CARVALHO, P. O. et al. Aplicação de lipases microbianas na obtenção de concentrados de ácidos graxos poliinsaturados. Química Nova, v. 26, n. 1, p.7580, 2003.

CASTANHEIRA, B., AFFONSO, M., SANTO, R. D. E. Epoxidação dos ésteres insaturados do óleo de soja seguida da fixação de $\mathrm{CO}_{2}$ para preparação de carbonatos e policarbonatos orgânicos. Disponível em: <http://prope.unesp.br/ xxi_cic/27_34677922861.pdf>. Acesso em: 10 jan. 2011.

CHEETAM, P. S. J. Principles of industrial biocatalysis and bioprocessing. In:Wiseman A, editor. Handbook of enzyme biotechnology. Ellis Horwood, 1995. p. 83-234

CONTI, R.; RODRIGUES, J. A. R.; MORAN, P. J. S. Biocatálise: avanços recentes. Química Nova, v. 24, n. 5, p.672-675, 2001.

EHRAN, S. Z., ASADAUSKAS, S. Lubrificant basestocks from vegetable oil. Industrial crops and products. v. 11, n. 2-3, p. 277-282, 2000.

ERHAN, S. Z.; SHARMA, B. K..; PEREZ, J. M. Oxidation and low temperature stability of vegetable oil-based lubricants. Industrial Crops and Products, v. 24, n. 7, p. 292-299, 2006.

HASAN, F.; SHAH, A. A.; HAMEED, A. Industrial applications of microbial lipases. Enzyme and Microbial Technology, v. 31, n. 2, p. 235-251, 2005.

LARA, L. R. S. Síntese químio- enzimática de ésteres metílicos epoxidados a partir do óleo de girassol utilizando lipase de Candida antarctica $B$ em sistemas com $\mathrm{CH}_{2} \mathrm{Cl}_{2} / \mathrm{H}_{2} \mathrm{O}$ e $\mathrm{CH}_{2} \mathrm{Cl}_{2}$, Trabalho de conclusão apresentado ao Curso de Química Industrial da Universidade de Santa Cruz do Sul, 2006.

LOUWRIER, A. Industrial products: the return to carbohydrate-based industries. Biotechnol Appl Biochem, v.27, n. 1, p. 1-8, 1998.

NETO, Pedro R. C. Obtenção de ésteres alquílicos (Biodiesel) por via enzimática a partir do óleo de soja. Dissertação de Mestrado-Curso de Mestrado- Curso de Pós-Graduação em Química. UFSC, 2002.

NUNES, M. R. S., MARTINELLI, M., PEDROSO, M. M. Epoxidação do óleo de mamona e derivados empregando o sistema catalítico VO (ACAC) $2 / T B H P$. Química Nova, v. 31, n. 4, 2008. 
OLIVEIRA, J. F. G.; ALVES, S. M. Adequação ambiental dos processos de usinagem utilizando Produção mais Limpa como estratégia de gestão ambiental. Jornal Produção, v. 17, n. 1, p. 129-138, 2007.

PORTE A. F. et al. Sunflower biodiesel production and application in family farms in Brazil. Fuel, v. 89, n. 12, p. 3718-3724, 2010.

SALIS, A.; PINNA, M.; MONDUZZI, M.; SOLINAS, V. Biodiesel production from triolein and short chain alcohols through biocatalysis. Journal of biotechnology. v. 119, n. 3, p. 291-299, 2005.

SAXENA R. K,; SHEORAN, A.; GIRI, B.; DAVIDSON, W. S. Purification strategies for microbial lipases. J. Microbiol Meth. v. 52, n. 1, p. 1-18, 2003.

SCHNEIDER, R. C. S.; LARA, L. R. S.; BITENCOURT, T. B.; NASCIMENTO, M. G.; NUNES, M. R. S. Chemo-Enzymatic Epoxidation of Sunflower Oil Methyl Esters J. Braz. Chem. Soc., v. 20, n. 8, p. 1473-1477, 2009.

WARWEL, S., KLAAS, M. R. Chemo-enzymatic epoxidation of unsatured carboxylic acids. Journal of Moleculas Catalysis B: Enzymatic. v. 1, n.1, p. 2935, 1995.

WICKERT. L. Produção de epóxidos de óleo de mamona. Trabalho de conclusão apresentado ao Curso de Química Industrial da Universidade de Santa Cruz do Sul, 2004.

ZEILMANN, R. P. Tendência aponta para a usinagem a seco. NEI: Informação industrial completa atualizada e completa. Disponível em: <http://www.nei. com.br/artigos/artigo.aspx?i=71>. Acesso em: 10 jan 2011.

ZEMAN, A.; SPRENGEL, A.; NIEDERMEIR, D.; SPATH, M. Biodegradable lubricants studies on thermo oxidation of metal-working fluids by differential scanning calorimetry. Thermochim Acta, v. 268, p. 9-15, 1995. 